\title{
Geografia e reprodução social
}

\author{
Geography and social reproduction
}

\begin{abstract}
Rafael Rossi'
RESUMO

O presente texto é um esforço investigativo de apresentação da particularidade do espaço geográfico a partir de suas origens históricas e ontológicas. Trata-se de uma empreitada que não desvincula o espaço da reprodução da sociedade enquanto totalidade ao longo do movimento histórico. Nesse aspecto, é fundamental entender a produção social em sentido amplo como produção também espacial que se complexificam e se dinamiza cada vez mais junto com a própria totalidade. Nossa abordagem, desse modo, é a partir da tradição filosófica conhecida como perspectiva ontológica que trata de traduzir a essência dos movimentos reais operantes na objetividade. Como conclusões salientamos a importância de entender a geografia em suas múltiplas relações com a totalidade e com o processo de autoconstrução humana, tanto em seus aspectos de possibilidades, quanto nos seus entraves, a partir da perspectiva de Lukács.
\end{abstract}

Palavras-chave: Espaço; Totalidade; Humanidade

\section{ABSTRACT}

The present text is an investigative effort to present the particularity of geographic space from its historical and ontological origins. It is an enterprise that does not disconnect the space of the reproduction of society as a totality throughout the historical movement. In this respect, it is fundamental to understand social production in the broad sense as also spatial production that is becoming increasingly complex and dynamic together with the totality itself. Our approach, therefore, is based on the philosophical tradition known as the ontological perspective that tries to translate the essence of the real operant movements into objectivity. As conclusions we emphasize the importance of understanding geography in its multiple relations with the totality and with the process of human self-construction, both in its aspects of possibilities as in its obstacles, from the perspective of Lukács.

Keywords: Space; Totality; Humanity.

\section{INTRODUÇÃO}

Estudar a geografia enquanto complexo social responsável pela produção e reprodução do espaço geográfico, incluindo todas suas dimensões territoriais, regionais e de lugares; pela abordagem ontológica é uma empreitada 'Docente na Faculdade de Educação e no Programa de Pós-Graduação em Educação da UFMS em Campo Grande - MS. E-mail: rafaelrossied@gmail.com Orcid-ID: https://orcid.org/0000-0001-8544-3756 
extremamente rara em ser observada na contemporaneidade. Não se trata de um exercício escolástico ou academicista descolado da realidade histórica e social construída pelos seres humanos. Ao contrário, trata-se, em verdade, de extrair do próprio processo histórico suas tendências mais essenciais no que concerne aos relacionamentos do espaço geográfico com os vários complexos sociais que conformam a realidade objetiva. Em outras palavras: estamos diante de um esforço mobilizado a partir da própria realidade, no sentido de apreensão dos limites e das potencialidades que a geografia apresenta na malha das sínteses históricas e sociais que conformam - na expressão lukacsiana - o "complexo de complexos" da reprodução social.

A ontologia instaurada desenvolvida por Lukács mostra, com bases respaldadas no processo histórico real, que no processo de produção do conhecimento sobre um determinado fenômeno social, devemos traduzir as tendências, dinâmicas e processos que se fazem presentes na própria realidade e não especular sobre os conceitos sem relacioná-los ao todo ao qual pertencem.

Com efeito, o procedimento metodológico para apreensão da geografia com a totalidade social deve ser procurado na história e no processo social em seus traços universais e na singularidade de suas objetivações em cada contexto. Justamente em razão disto que preferimos a expressão "onto-metodológica", pois ajuda a demarcar a prioridade ontológica da objetividade sobre a subjetividade. Não é, portanto, um desprezo da criatividade e destreza da subjetividade, mas o reconhecimento necessário da atitude de postar-se diante da realidade social com objetivo primeiro de extrair dela, revelar-lhe seus fundamentos estruturais de desenvolvimento e configuração. Como demonstraremos ao Iongo do texto, a produção espacial geográfica é determinada socialmente em função das demandas e das alternativas postas perante uma dada totalidade social. Não um determinismo mecanicista, mas em sentido ontológico, isto é, as possibilidades reais e concretas se encontram na realidade historicamente produzida e a consciência que se pretenda atingir um determinado objetivo precisa conhecer e 
desvendar estas alternativas existentes para alcançar a finalidade idealmente traçada.

Antes de avançar, entretanto, é imprescindível um alerta: totalidade não é sinônimo de tudo. A totalidade é mais do que a simples soma das partes. A totalidade social é sempre a rede, a malha, a síntese das diversas relações sociais que cada complexo da vida humana (arte, educação, trabalho, política, ciência, geografia etc.) desempenha entre si. Neste sentido, a totalidade apresenta sempre uma herança da dinâmica histórica e abriga as possibilidades para intervenção futura, isto é, ela é sempre "expressão do desenvolvimento histórico passado, da realização de algumas das potencialidades e possibilidades do passado no presente e, também, campo de possibilidade e desafios para o desenvolvimento futuro" (LESSA, 1999, p. 08).

Dessa maneira, para apreendermos a relação da geografia com a síntese qualitativa da totalidade social é preciso, em primeiro lugar, entender, mesmo que brevemente, o fundamento ontológico da práxis geográfica e do processo de reprodução social. Este fundamento é o trabalho. Não a forma concreta do trabalho de alguma formação social, como, por exemplo: o trabalho escravo, trabalho servil ou trabalho assalariado, mas sim, o trabalho enquanto intercâmbio orgânico da sociedade com a natureza para a produção de valores de uso. Qual a sua especificidade e o que faz dele a única categoria que funda o ser social, são temas que abordamos no item a seguir.

Num segundo momento, poderemos avançar para a compreensão do processo de reprodução social, mais especificamente, na relação que apresenta entre trabalho, totalidade e economia. Qual dessas dimensões exerce a função de “momento predominante" [Ubergreifendes Moment] é uma reflexão importantíssima para o debate geográfico, pois em toda relação social um complexo servirá de médium e de polo regente para a orientação geral dos demais. 
Por fim, em nossas considerações finais, ressaltamos as potencialidades investigativas que a perspectiva ontológica oferece a análise em geografia, não por alguma razão especulativa ou eruditista, mas por chamar à urgência histórica em analisar o processo histórico real em suas efetivas possibilidades e entraves e não fantasiar ou colocar nossos anseios acima daquilo concretamente existente no ser em-si dos objetos estudados.

\section{TRABALHO: FUNDAMENTO ONTOLÓGICO DA GEOGRAFIA E DA TOTALIDADE} SOCIAL

Antes de explicitar as relações da geografia com a totalidade no processo de reprodução da sociedade, isto é, na dinâmica de autoconstrução humana, é preciso compreender, preliminarmente, qual é a base histórica e real que possibilita o surgimento da humanidade e a complexificação da sociedade. Este papel caberá ao trabalho, enquanto única categoria fundante do ser social. Não estamos tratando, todavia, do trabalho assalariado que é a matriz fundante do capitalismo. Estamos nos referindo ao trabalho enquanto atividade humana que exerce a transformação da natureza para a produção de valores de uso.

Lukács nos alerta que nenhuma categoria pode ser considerada isoladamente. Com efeito, a discussão do trabalho aparece de modo didático e exemplar, entretanto, o próprio trabalho está imbrincado à “linguagem, a cooperação e a divisão do trabalho" (LUKÁCS, 1981, p. 01). Porém, é apenas com o trabalho que o ser social se origina, pois com ele "surgem novas relações da consciência com a realidade" (LUKÁCS, 1981, p. 01).

A essência do trabalho está em ser uma categoria inerente à “luta pela existência" humana e, além disso, apresentar em "todos os seus estádios" produtos “da auto-atividade do homem" (LUKÁCS, 1981, p. 04). Ou seja:

Considerando que nos ocupamos do complexo concreto da sociabilidade como forma de ser, poder-se-ia legitimamente perguntar por que, de todo esse complexo, colocamos o acento exatamente no trabalho e lhe atribuímos 
um lugar tão privilegiado no processo e no salto da gênese do ser social. A resposta, em termos ontológicos, é mais simples do que parece ser à primeira vista: todas as outras categorias desta forma de ser tem já, essencialmente, um caráter puramente social; suas propriedades e seus modos de operar somente se desdobram no ser social já constituído; quaisquer manifestações delas, ainda que sejam muito primitivas, pressupõem o salto como já consumado. Somente o trabalho tem, como sua essência ontológica, um claro caráter intermediário: ele é, essencialmente, uma interrelação entre homem (sociedade) e natureza, tanto inorgânica (utensílio, matéria-prima, objeto do trabalho, etc.) como orgânica, interrelação que pode até estar situada em pontos determinados da série a que nos referimos, mas antes de mais nada assinala a passagem, no homem que trabalha, do ser meramente biológico ao ser social (LUKÁCS, 1981, p. 04, grifos nossos).

Com o trabalho a consciência humana se modifica substancialmente da atividade dos animais. Certamente os animais transformam a natureza, mas a transformação da natureza em valores de uso que é operada pela atividade humana faz com que, irrevogavelmente, se amplie o leque de possibilidades para intervir na realidade e compreendê-la. Este processo faz surgir todas as dimensões sociais: educação, política, geografia, ciência, arte; etc.

Em razão disto, a estrutura interna do trabalho (busca dos meios e objetivação) também se fará presente, com as devidas mediações, na estrutura dos demais complexos humanos. Por isso que "o trabalho pode ser considerado o fenômeno originário, o modelo do ser social" (LUKÁCS, 1981, p. 05). Com o trabalho surge um efetivo pôr teleológico. Isto significa que "todo processo teleológico implica numa finalidade e, portanto, numa consciência que estabelece fins" e o "pôr", neste caso, indica que "a consciência dá início a um processo real, exatamente o processo teleológico" (LUKÁCS, 1981, p. 09).

Dessa forma, Santos corretamente pondera que "para que o animal homem se torne homem social, é indispensável que ele também se torne o centro da natureza" e isto "ele consegue pelo uso consciente dos instrumentos de trabalho" e, com isso, nesse momento "a atividade social começa a ser uma simbiose entre trabalho do homem e uma natureza cada vez mais modificada por esse mesmo trabalho", sendo que esta dinâmica seria impossível sem um "mínimo de 
organização social e sem uma organização paralela do espaço" (SANTOS, 2004, p. 201-202).

Lukács utiliza o exemplo de construção de uma casa utilizado por Aristóteles. Vejamos:

A casa tem um ser material tanto quanto a pedra, a madeira, etc; no entanto, a posição teleológica faz surgir uma objetividade inteiramente diferente com relação aos elementos primitivos. Nenhum desenvolvimento imanente das propriedades, das legalidades e das forças operantes no mero ser-em-si da pedra ou da madeira pode fazer "derivar" uma casa. Para que isto aconteça é necessário o poder do pensamento e da vontade humana, que organize material e fundamentalmente tais propriedades de uma forma inteiramente nova (LUKÁCS, 1981, p. 14).

Isto nos mostra que: 1) a consciência é indispensável e, de fato, possui um papel ativo na produção da vida em sociedade; 2) a consciência possui uma autonomia relativa frente à objetividade, isto é, ela deve refletir, pensar em articulações e vínculos a partir dos elementos presentes na própria realidade, caso contrário a finalidade previamente traçada não poderá ser objetivada e; 3) o campo de possibilidades para a consciência atuar cabe à objetividade. Estes parâmetros são indispensáveis para evitarmos tanto o idealismo que supervaloriza o papel da consciência, quanto o materialismo mecanicista que, por outro lado, despreza a subjetividade na construção social.

Lessa (2016) nos explica que com o trabalho as possibilidades de transformação da natureza são apropriadas pela consciência e refletidas sobre a sua objetivação. Em outras palavras:

Ao serem apropriadas pela consciência, possibilitam que os seres humanos avaliem qual a melhor possibilidade para atender a necessidade mais urgente e, assim, elaborem um projeto, um plano (na filosofia: uma teleologia, isto é, uma ideia que irá dirigir a prática subsequente). Decidem, digamos, que para atender à necessidade por calor e proteção para aquela noite, farão uma fogueira. A ideia da fogueira está na consciência - tão somente. Por isso a ideia não produz nem o calor nem a proteção desejadas. Para tanto é preciso que, com o uso do corpo humano (pois é este a única porção da natureza em interação direta, imediata, com a consciência), sejam reunidas as madeiras, pedras etc. e que a fogueira seja o resultado de uma ação humana. Se o fogo existe na natureza, a fogueira apenas existe como ação humana que organizou a madeira e as pedras de modo a que cumprisse uma função social: aquecer e proteger naquela noite (LESSA, 2016, p. 327). 
Com este processo não só a natureza foi transformada, mas as próprias individualidades humanas que passam a contar, após os atos de trabalho, com novos conhecimentos, novas habilidades, técnicas, valores etc. que podem ser utilizados em diversas outras situações e, com isso, temos, portanto, o fundamento de todos os complexos sociais e da natureza da reprodução social: a produção incessante do novo, novas necessidades sociais, novas possibilidades de transformação. Em linhas gerais três são as características gerais desta dinâmica social despertada à vida pelo trabalho:

O desenvolvimento das capacidades produtivas possibilitam sociedades e relações sociais que abarcam uma porção cada vez maior da humanidade. Das sociedades primitivas, bandos e tribos, por milhares de anos de evolução, passamos à situação presente em que um mercado mundial articula a vida de cada indivíduo à existência de todos os humanos do planeta. Dizemos que o gênero humano, que no início era basicamente biológico, se elevou a um gênero social, isto é, elevou-se a um patamar de desenvolvimento social que articula, de fato, a vida de todos os indivíduos em uma mesma e única história, a história da humanidade.

A segunda característica, é que essa evolução repete algo que já encontramos na matéria inorgânica e orgânica: a tendência de se passar de níveis mais homogêneos e simples a patamares mais complexos e heterogêneos. $\mathrm{Na}$ história dos seres humanos, isto ocorre em um duplo processo: a personalidade dos indivíduos vai se tornando cada vez mais complexa, cada vez mais mediada e os indivíduos são capazes de ações, de comportamentos, cada vez mais complexos, matizados e sofisticados. E isto ocorre porque o desenvolvimento social coloca frente aos indivíduos possibilidades e necessidades que são, também elas, mais complexas e requerem dos indivíduos comportamentos, ações, cada vez mais complexos e mediados. Tal como no inorgânico e na vida, vamos também do simples ao complexo. Evidentemente isso não se conflita com o afirmado no item 10, acima. Apenas uma humanidade mais complexa e desenvolvida é capaz de ser portadora de uma relação social que articule a vida de cada um a vida de todos no planeta (o mercado mundial etc.)

A terceira característica é que, quanto maior a capacidade humana em tirar da natureza o que necessitamos, menos horas e menos pessoas precisam ser empregadas nessa tarefa. Se, na sociedade primitiva, todos o indivíduos, praticamente por todas as horas do dia, coletavam da natureza o que necessitavam - hoje, nas sociedades mais desenvolvidas, menos de $12 \%$ da força de trabalho é empregada nas indústrias e na agricultura, atividades em que temos a transformação da natureza. As sociedades em que vivemos são agudas testemunhas de uma decrescente necessidade por trabalhadores: o desemprego que não nos deixe mentir. Apesar de haver riqueza para manter a todos os humanos no planeta, vivemos desigualdades sociais crescentes, não pela falta de produtos, mas porque o capital não possibilita a distribuição da 
riqueza de forma igualitária. O esgotamento histórico do capitalismo é resultante dessa tendência universal do desenvolvimento humano: precisamos trabalhar cada vez menos para produzir o que necessitamos (LESSA, 2016, p. 331-332, grifos nossos).

Em suma: sociedades mais complexas, um espaço geográfico mais dinâmico e inter-relacionado, maior desenvolvimento das forças produtivas (técnica, ciência, tecnologia e capacidade humana) e menor gasto de energia para a transformação da natureza. Essa é a marca indelével da reprodução social. O espaço geográfico produzido desde os primórdios surge, portanto, em função da capacidade humana em efetivar atos de trabalho e isto significa que a práxis geográfica deve sua existência à articulação nova entre consciência e realidade objetiva que se origina com o trabalho: o pôr teleológico. Obviamente esta mesma práxis geográfica se complexifica, se desenvolve e se dinamiza e isso em razão do aumento social das múltiplas interações que desempenhará com os demais complexos da vida humana. Aqui reside a importância em analisarmos, rapidamente, as linhas gerais da reprodução social como apresentamos a seguir.

\section{REPRODUÇÃO SOCIAL: AUTONOMIA E DEPENDÊNCIA DO ESPAÇO}

\section{GEOGRÁFICO}

O esclarecimento do trabalho como fundamento do ser social e, portanto, da práxis geográfica é indispensável para o entendimento da complexificação que se opera na reprodução social. Ao contrário da reprodução biológica que há sempre a reposição do mesmo, na reprodução social ocorre sempre a produção do novo. Vejamos melhor:

[...] o trabalho (e toda atividade social que, em última análise, parte dele e volta a desembocar nele) confronta todo homem com novas tarefas, cuja execução desperta nele novas capacidades; em segundo lugar, os produtos do trabalho satisfazem as necessidades humanas de uma maneira nova, que se afasta cada vez mais da satisfação biológica das necessidades, mas sem jamais dissociar-se totalmente dela; de fato, o trabalho e os produtos do trabalho introduzem na vida necessidades sempre novas e até ali desconhecidas e, com elas, novos modos de satisfazê-las. Em suma: tornando a reprodução da vida cada vez mais multiforme, cada vez mais complexa, distanciando-a cada vez mais da reprodução meramente biológica, 
eles transformam simultaneamente também os homens que efetuam a práxis, afastam-no cada vez mais da reprodução meramente biológica de sua vida. Em outros contextos já mostramos o efeito que essa modificação do modo de vida pelo trabalho tem sobre as manifestações vitais biológicas eminentes, como alimentação, sexualidade etc. No entanto, nunca será demais reiterar enfaticamente que, nesse processo, a base biológica jamais é suprimida, mas apenas socializada, sendo que por essa via nascem no homem propriedades, faculdades qualitativamente, estruturalmente novas de seu serhomem (LUKÁCS, 2013, p. 291, grifos nossos).

Este riquíssimo trecho do Lukács é importantíssimo para a reflexão proposta aqui em tela. O processo de reprodução social, baseado no trabalho, não se resume nesta atividade. Com o pôr teleológico desencadeado pela atividade laborativa, há a produção de novas necessidades e novas possibilidades de compreensão e transformação da realidade natural. Esta dinâmica, por sua vez, permite à consciência humana acumular os valores, conhecimentos, habilidades, técnicas etc. e utilizá-los em uma série diversas de outras situações e atividades. Com efeito, abre-se a possibilidade para despertar novas dimensões sociais que irão interagir entre si e, com isto, estamos assistindo ao fundamento ontológico da própria totalidade social enquanto síntese qualitativa das múltiplas interações de uma determinada sociabilidade.

É também esta dinâmica que possibilita a crescente complexificação e socialização da vida humana, num processo que o filósofo húngaro denominou de "afastamento das barreiras naturais". Note o leitor que se trata de um "afastamento" e não um rompimento absoluto. Um exemplo: a fome continua a ser uma necessidade biológica de nosso corpo, todavia, a maneira como saciamos a fome é imensamente/qualitativamente mais social. Poderíamos pensar ainda em vários outros exemplos, inclusive aqui, a complexificação social do próprio espaço geográfico. Se na Antiguidade um aumento das chuvas poderia causar grandes problemas na vida daquelas sociedades, hoje, os japoneses, por exemplo, conseguem lidar de um modo socialmente extraordinário com seus terremotos e tsunamis. O arranha-céu Burj Khalifa Bin Zayid, em Dubai, para pensarmos em outro exemplo de afastamento das barreiras naturais, atinge a impressionante altura de 828 m, com 160 andares. Em todos os casos, estamos 
diante do resultado da interação social dos vários complexos que constituem o ser social, no incessante processo de produção do novo: novas possibilidades, novas necessidades, novas alternativas e novas respostas.

Em última instância, o fundamento ontológico no qual se baseia a reprodução social e o afastamento das barreiras naturais reside no pressuposto ineliminável de que: “os atos do trabalho apontam necessária e ininterruptamente para além de si mesmos" (LUKÁCS, 2013, p. 160). Também aqui é o trabalho - enquanto intercâmbio orgânico da sociedade com a natureza para a produção de valores de uso - a dinâmica que impulsiona a complexificação e desenvolvimento do espaço geográfico. Como já alertamos, não se trata de um rompimento absoluto com a natureza. Sem o intercâmbio com a natureza não há ser social, ou seja, não existe humanidade. Trata-se da interação cada vez mais social que os complexos e as categorias assumem na vida humana. Em outras palavras o "princípio originalmente biológico de diferenciação acolhe cada vez mais momentos do social e estes assumem um papel predominante nela, degradando os momentos biológicos à condição de momentos secundários" (LUKÁCS, 2013, p. 162).

Fundamental, portanto, notar que a gênese do espaço geográfico está presente no momento em que os seres humanos começam a produzir de modo intencional as condições materiais da vida social. Por isso que 'o ato de produzir é igualmente o ato de produzir o espaço", pois "a promoção do homem animal a homem social deu-se quando ele começou a produzir" e a produção supõe "uma intermediação entre o homem e a natureza, através das técnicas e dos instrumentos de trabalho inventados para o exercício desse intermédio" (SANTOS, 2004, p. 202).

Nesse aspecto, o início da produção social, ocorre quando os homens começam a trabalhar "em um regime de cooperação, isto é, em sociedade, a fim de alcançar os objetivos que haviam antecipadamente concebido, antes mesmo de começar a trabalhar" e, dessa maneira, "a produção é a utilização consciente 
dos instrumentos de trabalho com um objetivo definido, isto é, o objetivo de alcançar um resultado preestabelecido", portanto, produzir e produzir o espaço são dois atos indissociáveis (SANTOS, 2004, p. 202-203).

Entre o trabalho e o espaço geográfico ou qualquer outra dimensão social passa a se estabelecer assim uma rede intrincada e complexa de interações sociais que possui por mediação a própria totalidade. Ou seja: "a constante reprodução de trabalho, divisão do trabalho etc. torna esse médium da mediação cada vez mais emaranhado, cada vez mais denso, abrangendo cada vez mais todo o ser dos homens", todavia, mais uma vez, todos estes complexos da vida em sociedade radicam na "origem ontológica no metabolismo da sociedade com a natureza" (LUKÁCS, 2013, p. 205).

Em razão destes entendimentos que podemos considerar o "espaço total e o espaço local" como "aspectos de uma única e mesma realidade - a realidade total - à imagem do universal e dos particulares", já que a sociedade como um todo e o espaço enquanto todo "se transformam através do tempo, num movimento que, embora interessando igualmente às diversas frações da sociedade e do espaço, é o resultado da interação entre sociedade global e espaço global e de suas diversas frações" (SANTOS, 2004, p. 208). A totalidade se configura enquanto força, enquanto campo de orientação e, dessa forma, "cada acontecer particular representa uma determinação da sociedade como um todo e um lugar próprio que o define, acrescentando à sua dimensão social original, uma dimensão que é, de uma só vez, temporal e espacial" (SANTOS, 2004, p. 219).

Como já argumentamos, também, entre o trabalho e cada um dos complexos humanos há a mediação rica e intrincada da própria totalidade enquanto síntese das múltiplas determinações recíprocas que se desenvolvem no ser social. Por outro lado, seria também equivocado desprezar apressadamente a interação que a economia - no sentido assinalado - estabelece. Trabalho e economia, deste modo, conformam o momento predominante na orientação geral da própria totalidade social e esta última, por sua vez, é o momento predominante 
na atuação, nas demandas e nos limites de cada dimensão da vida humana. Não há uma autonomia absoluta entre espaço geográfico e trabalho e totalidade social, por exemplo. A esse respeito Lukács argumenta que “a representação fetichizante-idealista da independência absoluta dos complexos singulares, tão frequente nas ciências históricas e sociais, parte, por um lado, de uma representação estreitada e reificada do econômico" (LUKÁCS, 2013, p. 196).

O fato dos complexos sociais, incluso o espaço geográfico, ser desigual e permitir um acesso diferenciado na sua produção e apropriação não significa uma característica interna à sua própria constituição. Antes disso, indica a consequência da relação da geografia com a totalidade social consubstanciada com base na exploração no processo de trabalho. A humanidade desenvolveu as bases materiais para uma construção eminentemente positiva e autêntica do gênero humano em suas diversas individualidades. Isto é: “o ser-para-si do gênero humano é, portanto, o resultado de um processo, que se desenrola tanto na produção econômico-objetiva global como na reprodução dos homens singulares" (LUKÁCS, 2013, p. 351).

Uma consideração neste aspecto é extremamente importante: as possibilidades de apropriação e produção do espaço geográfico. Já vimos como que a produção do espaço geográfico é desigual e guarda íntima relação com o processo histórico de reprodução social. Trata-se, em verdade, de um espaço produzido pela ação dos indivíduos em sociedade a partir das demandas delimitadas socialmente. Não por um acaso qualquer teremos, no espaço geográfico, territórios de decisão, territórios de riqueza e, ao mesmo tempo, territórios de miséria, de segregação e desigualdades.

Sem dúvida, em todos os casos, estamos assistindo um processo de produção do espaço geográfico efetivado concretamente pela atividade consciente dos indivíduos em sociedade. Todavia, como toda sociedade se baseia numa forma específica de estabelecer o intercâmbio orgânico da sociedade com a natureza para a produção de valores de uso (trabalho), temos que prestar 
atenção no fato de que um processo de trabalho que contenha em si qualquer tipo de exploração do homem pelo homem, conterá, irrevogavelmente, uma desigual produção e apropriação das potencialidades contidas no espaço geográfico. No processo de reprodução social está gravado, em germe, a natureza da produção espacial geográfica.

Como já afirmamos, os indivíduos produzem e reagem ativamente à produção geográfica do espaço. Porém, as possibilidades concretas do grau de utilização e da qualidade desta apropriação encontram irradiações operantes no movimento posto em prática pelas classes sociais. Residir em um município pleno de museus, teatros e cinemas, por exemplo, não significa que todos os indivíduos poderão usufruir destes bens culturais. A possibilidade real e concreta não se encontra na "vontade subjetiva" apenas dos indivíduos, mas na objetividade de suas relações sociais que facilitarão ou obstaculizarão a realização desta apropriação geográfica e cultural. Com isto, evita-se tanto o idealismo de acreditar numa autonomia absoluta dos indivíduos perante o espaço geográfico e deste perante uma respectiva totalidade social construída historicamente e, ao mesmo tempo, está descartado o materialismo mecanicista que não consegue apreender o papel ativo dos indivíduos e do próprio complexo espacial geográfico na interação com a vida em sociedade.

Estamos diante, portanto, da "prioridade ontológica da produção enquanto momento predominante" (LUKÁCS, 2012, p. 331). Prioridade ontológica significa que o trabalho e a economia colocam os rumos, por intermédio da totalidade, a cada complexo social, incluindo a geografia. Não se trata de um determinismo mecanicista, mas sim da apreensão de que na interação social sempre existe um "momento predominante", ou seja, sempre existe um campo de limites e possibilidades criado pelo trabalho e pela economia e manifestado de modo mediado através da totalidade social.

Importante ainda, a título de finalização, que a produção é entendida em seu sentido amplo/ontológico, enquanto produção e reprodução da "vida 
humana, que até mesmo em seus estágios extremamente primitivos (o pastoreio dos mongóis) vai muito além da mera conservação biológica, não podendo portanto deixar de ter um acentuado caráter econômico-social" e com isto "é essa forma geral da produção que determina a distribuição", já que "o desenvolvimento essencial do ser humano é determinado pela maneira como ele produz" (LUKÁCS, 2012, p. 336). Aqui está a importância de apreender o processo histórico e geográfico, pois:

Com efeito, a Coisa mesma não se esgota em seu fim, mas em sua atualização; nem o resultado é o todo efetivo, mas sim o resultado junto com o seu vir-aser. O fim para si é o universal sem vida, como a tendência é o mero impulso ainda carente de sua efetividade; o resultado nu é o cadáver que deixou atrás de si a tendência. Igualmente, a diversidade é, antes, o limite da Coisa: está ali onde a Coisa deixa de ser; ou é o que a mesma não é (HEGEL, 1992, p. 23).

A geografia, enquanto complexo social que acompanha o desenvolvimento do ser social, se consubstancia naquela dimensão humana que possui por função, no processo de reprodução social, a produção e reprodução do espaço geográfico. Para demonstrar este entendimento partimos de pressupostos reais e historicamente comprovados: o surgimento do ser social a partir do trabalho. Nesse aspecto, o trabalho pode ser considerado a única categoria que funda a sociabilidade, pois apresenta uma articulação inteiramente nova entre teleologia e causalidade, ou em outros termos, entre consciência e objetividade. Ao estabelecer fins a ser alcançados, a consciência humana passa a ter um papel extremamente ativo na produção da vida em sociedade. Todavia, ao contrário do idealismo, isto não significa que ela possa realizar tudo que imaginar. Caberá à consciência humana articular, refletir e pensar adequadamente os elementos presentes na realidade objetiva para que o fim previamente delineado possa ser atingido.

Não por um acaso qualquer Lukács utilize a expressão "pôr teleológico", pois não se trata tão somente de estabelecer fins, mas de objetivar uma criação eminentemente humana e social que não derivaria do próprio movimento da natureza. Como já citado anteriormente, uma casa apresenta em sua estrutura 
areia e pedras, mas do automovimento natural destes elementos não resulta uma casa. Esta última é fruto da ação conscientemente dirigida pelos atos humanos em processo de trabalho.

Uma importante distinção diz respeito aos pores teleológicos primários e os pores teleológicos secundários. Os primeiros dizem respeito à incidência sobre algum objeto natural para sua transformação em meios de produção ou de subsistência e os segundos, por sua vez, visam, como explica Lukács (2013), atingir a consciência de um homem ou grupo de homens para que eles possam efetuar novas posições teleológicas. Entendemos que o espaço geográfico deve sua existência à capacidade humana em realizar atos de trabalho, pois aqui se verifica o salto ontológico do ser meramente biológico ao ser social, com uma articulação nova entre consciência e realidade, como demonstramos no primeiro item deste artigo. Entretanto, com o desenvolvimento e a complexificação do próprio gênero humano a práxis geográfica passa, cada vez mais, a interagir com outras dimensões da vida humana a partir dos limites, entraves e possibilidades que uma totalidade historicamente construída lhe dispõe.

No processo de trabalho, mesmo em fases iniciais, já se instaura posições de "finalidades imediatas" e "finalidades mais mediatas", por exemplo, podemos pensar, no exemplo elencado por Lukács, na fabricação de armas que envolve várias posições teleológicas diversas e heterogêneas. Novamente, aqui, é afirmado o papel do trabalho em transformar a natureza e, também, a natureza do homem que trabalha, sendo a linha desse processo de mudança a "posição teleológica e pela realização prática desta". Neste processo o homem chega a "um domínio consciente sobre si mesmo". O objetivo existe na consciência antes de sua realização material e, ao mesmo tempo, em cada movimento singular, verificando de forma "crítica e consciente" se se almeja o melhor resultado possível de seu trabalho. O domínio da consciência sobre o próprio corpo, hábitos, instintos e afetos é, de acordo com Lukács, uma condição elementar já do trabalho em seus estágios mais primitivos. Assim, tal dinâmica marca 
“decididamente as representações que o homem faz de si mesmo, uma vez que exige uma relação consigo mesmo qualitativamente diferente" e, por conseguinte, "inteiramente heterogênea em relação à condição animal, uma vez que tais exigências são apresentadas por todo tipo de trabalho" (LUKÁCS, 1981, p. 98).

Um aspecto decisivo neste debate, de acordo com nosso autor, diz respeito ao recuo das barreiras naturais provocado pelo trabalho e que tem na consciência um importante apoio por operar "posições teleológicas da práxis". Com efeito, trata-se de um "contínuo recuo das barreiras naturais" e não uma supressão completa, pois a base biológica humana continua existindo, ou seja, há uma "ligação ontológica" da sociedade para com a natureza e da "consciência com o processo vital do corpo" (LUKÁCS, 1981, p. 99).

Nesse sentido, tanto a existência e a "atividade da consciência" estão ligados de modo indissolúvel "ao desenvolvimento biológico do organismo vivo", quanto a consciência cumpre uma "função dirigente, de guia, determinante" com relação ao corpo. Papel este que, para Lukács, tem sua origem no trabalho. Assim, é preciso compreender que, do ponto de vista ontológico, é possível a existência de um corpo sem consciência, como, por exemplo, no caso de alguma doença. Porém, também nesta circunstância, a consciência não perde seu papel de guia, sua função dirigente.

Nossa sociedade não é um todo harmônico e pacífico. À tranquilidade do sono de alguns, se contrapõe o desespero de milhões ao não saber como irão conseguir a próxima refeição. Todavia, nunca antes na história da humanidade desenvolvemos um processo de produção da vida social, incluindo aqui do espaço geográfico, tão desenvolvido, complexo e universal. Poderíamos mesmo afirmar que é o primeiro momento histórico em que, de fato, temos a humanidade no sentido do seu reconhecimento global e no que se refere aos intercâmbios entre as diversas nações. 
Grande parte destas conquistas se deve ao surpreendente avanço científico, técnico e tecnológico que acompanha a atual forma de sociabilidade. Trata-se, em verdade, de uma tendência gravada em germe na capacidade humana em transformar a natureza de modo intencional para o atendimento de alguma necessidade da vida social. Isto é: o trabalho, nesse sentido de transformação da natureza, apresenta, in status nascendi a dinâmica que garante a criação de novos conhecimentos, novas habilidades, novas técnicas que, por sua vez, impulsionam o desenvolvimento e a complexificação da ciência e do próprio espaço geográfico.

Com a trajetória histórica, certamente várias outras dimensões sociais, para além do trabalho, irão interagir com a ciência e com o espaço, acentuando ainda mais a sua universalidade e progresso. Trata-se, do que chamamos de amplitude conquistada. Em nossa sociedade pudemos criar avanços científicos extraordinários: máquinas que realizam o trabalho de dezenas de trabalhadores; equipamentos que nos mostram organismos celulares; instrumentos grandiosos que possibilitam a aceleração dos átomos; tratamentos médicos capazes de garantir uma boa qualidade de vida a enfermos; satélites capazes de nos mostrar imagens de estrelas a milhares de anos luz da Terra etc. etc. etc.

Essa mesma amplitude conquistada também se manifesta no espaço geográfico. De fato: o espaço geográfico da contemporaneidade é uma conquista, uma expressão e condição do progresso social. Isto, todavia, não significa que ele apresente todas as suas potencialidades e oportunidades de modo homogêneo para a totalidade dos indivíduos. Habitantes de um mesmo município dispõem de desiguais oportunidades reais de participação no espaço geográfico. Podem existir centros de pesquisa e de ensino de excelência ao lado de grandes periferias. 0 acesso ao dinheiro, o local ocupado no processo global de tomada de decisões, a atividade exercida, etc. são elementos que influenciam sobremaneira na qualidade da interação das pessoas com o espaço geográfico em seus aspectos culturais, científicos e espaciais. O fato de existir, por exemplo, grandes teatros 
em uma metrópole não significa que todos os seus habitantes poderão usufruir de seus espetáculos. O dinheiro e a classe estruturam as fronteiras que, efetivamente, se consubstanciam em grandes cordilheiras entre os indivíduos e as benesses conquistadas pelo gênero humano em seus aspectos espaçointelectuais.

Produzimos mais alimentos do que a capacidade de todos os habitantes do planeta de consumi-los; desenvolvemos tecnologias capazes de nos fazer trabalhar menos e, ainda assim, trabalhamos intensamente e convivemos em nossa sociedade com milhões de pessoas em trabalho escravo, pobreza e miséria. Produzimos tecnologias na área da saúde espetaculares, todavia, somente estarão disponíveis a quem puder pagar por elas. Conquistamos um desenvolvimento das forças produtivas capaz de produzir tudo aquilo que necessitamos preservando o meio ambiente e, mesmo assim, em nome do lucro e do "bem dos negócios", todos os dias a poluição e o desmatamento se manifestam por todo o globo.

Chegamos à estreiteza imposta. Conquistamos um amplo desenvolvimento e o convertemos em limites estreitos que devem obedecer, acima de tudo e de todos, a reprodução dos lucros e dos negócios, o "sagrado" mercado. Nesta sociedade o dinheiro é o princípio maior das possibilidades que podem garantir ou não a ultrapassagem das fronteiras no espaço geográfico: a fronteira da educação, da cultura, da comida, da moradia, do conhecimento, da ciência... Enquanto o bem das empresas for colocado no alto da hierarquia, subordinando todo o resto, continuaremos a estreitar, cada vez mais, nossa história conquistada, nossa amplitude espacial, científica e cultural. É como se a velha fábula do gênio e da lâmpada agora se estendesse à toda humanidade: poderes e potências grandiosíssimos, circunscritos nos estreitos limites impostos pelo mercado.

Este avanço enorme da ciência e da complexidade do espaço geográfico se conforma em horizontalidades hierarquicamente, isto é, verticalmente, 
comandadas pelas demandas das empresas dominantes. Se conformam, portanto, em potências para uma outra história, para outra forma de sociabilidade efetivamente livre e autônoma, que preze pelo atendimento das verdadeiras e essenciais necessidades humanas. Potências estas que, no presente, são geograficizadas, na prática, a serviço dos agentes econômicos que ocupam local de destaque. O que é potência para a humanidade, em suas autênticas demandas, se converte em geografia a favor da reprodução dos lucros e da exploração; portanto, objetivos anti-humanitários.

\section{CONSIDERAÇÕES FINAIS}

O espaço geográfico, de modo mediado, terá sua produção e reprodução delineadas a partir das mediações colocadas pelo campo de limites e possibilidades instaurado pela totalidade social, sendo esta, por sua vez, baseada numa forma específica de estabelecer o intercâmbio entre a sociedade e a natureza na produção dos valores de uso. Isto é: toda totalidade social se funda em uma forma típica de trabalho. Entre o trabalho e a produção do espaço geográfico há, portanto, a mediação da totalidade social enquanto síntese das múltiplas interações numa dada formação social.

A produção deve ser entendida em sentido amplo, como Lukács (2012) nos esclarece, ou seja, produção também de modos de vida, de pensamento, de cultura. Entretanto, há que se observar que esta produção social - física e espiritual - parte de um pressuposto prático: a forma como os seres humanos se relacionam entre si no processo de transformação da natureza.

O que a análise da realidade nos apresenta é a possibilidade real de desenvolvimento que tenha como parâmetro o conjunto do gênero humano. Isto não é uma especulação, mas sim, uma constatação do fantástico nível de capacidade produtiva alcançado em nossos tempos. O desafio, portanto, do ponto de vista do mundo e da vida e não da estreita perspectiva do mercado, é 
converter esta potência produtiva em concreto processo societário humanamente emancipado.

Para os pesquisadores e professores de Geografia a tarefa que o presente nos coloca é: 1) a apropriação e transmissão dos clássicos que possibilitem uma compreensão da essência do movimento da realidade ao longo do processo histórico e; 2) a compreensão efetivamente crítica da produção sócio-espacial do presente em suas desigualdades, potências e entraves. Quais as possibilidades reais para a produção do espaço? E, por conseguinte, como tais possibilidades estão sendo geografizadas hoje?

Trata-se, dessa forma, de duas empreitadas extremamente relevantes no ensino e na pesquisa. A contribuição com a produção e disseminação de um conhecimento teórico que possibilite o entendimento da articulação das dinâmicas essenciais em suas manifestações concretas e aparentes no espaço, nos territórios e nos lugares; ao mesmo tempo, o exercício da crítica que, justamente por confrontar as teorias com a realidade em todos os seus aspectos (históricos, econômicos, geográficos etc.) auxilia no esclarecimento dos fatos e das articulações entre os fenômenos.

Perante um cotidiano que incentiva a confusão e a miopia diante da vida e da sociedade, mais do que nunca, a ciência e a crítica são chamadas a ocupar seu local de destaque no compromisso intransigente com a humanidade.

O ser humano e o gênero, precisa aparecer como centro da produção científica, geográfica, enfim da produção social em sentido amplo. Esta necessidade é urgente em face da gravidade estrutural dos problemas que enfrentamos que são insolúveis por intervenções simplificadoras e localistas.

\section{REFERÊNCIAS}

HEGEL, G. W. F. Fenomenologia do Espírito - Parte I. 2ª ed. Petrópolis: Vozes, 1992. 
LESSA, S. O processo de produção/reprodução social: trabalho e sociabilidade. Capacitação em Serviço Social e Política Social, Módulo 2, pp. 20-33, CEAD-UNB, 1999.

LESSA, S. Posfácio - Possibilidade, Lei e Acaso: Os físicos e seus incríveis cíclotrons. In: VEDDA, M.; COSTA, G.; ALCÂNTARA, N. (orgs.). Anuário Lukács. São Paulo: Instituto Lukács, p. 313-366, 2016.

LUKÁCS, G. II Lavoro. In: Per una Ontologia dell'essere sociale. Roma: Riuniti, 1981, p. 11-131. (Tradução Mimeo.de Ivo Tonet, 145p.)

LUKÁCS, G. Para uma ontologia do ser social - I. São Paulo: Boitempo: 2012.

LUKÁCS, G. Para uma ontologia do ser social - II. São Paulo: Boitempo: 2013.

LUKÁCS, G. Conversando com Lukács: entrevista a Léo Kofler, Wolfang Abendroth e Hans Heinz Holz/Georg Lukács. Tradução de Gisieh Vianna. São Paulo: Instituto Lukács, 2014.

SANTOS, M. Por uma Geografia Nova - Da Crítica da Geografia a uma Geografia Crítica. 6ª ed. São Paulo: Editora da Universidade de São Paulo, 2004. 